\title{
Optimization of culture conditions for Gardnerella vaginalis biofilm formation
}

\author{
Daniela Machado a, Ana Palmeira-de-Oliveira ${ }^{\mathrm{b}, \mathrm{c}}$, Nuno Cerca ${ }^{\mathrm{a}, *}$ \\ a Centre of Biological Engineering, LIBRO - Laboratory of Research in Biofilms Rosário Oliveira, University of Minho, Campus de Gualtar, 4710-057 Braga, Portugal \\ ${ }^{\mathrm{b}}$ CICS-UBI, Health Sciences Research Center, Faculty of Health Sciences, University of Beira Interior, Avenida Infante D. Henrique, 6200-506 Covilhã, Portugal \\ c Labfit - HPRD: Health Products Research and Development Lda, Edificio UBIMEDICAL, Estrada Municipal 506, 6200-284 Covilhã, Portugal
}

\section{A R T I C L E I N F O}

\section{Article history:}

Received 11 June 2015

Received in revised form 10 September 2015

Accepted 10 September 2015

Available online 14 September 2015

\section{Keywords:}

Bacterial vaginosis

Biofilms

Gardnerella vaginalis

Clinical isolates

\begin{abstract}
A B S T R A C T
Bacterial vaginosis is the leading vaginal disorder in women in reproductive age. Although bacterial vaginosis is related with presence of a biofilm composed predominantly by Gardnerella vaginalis, there has not been a detailed information addressing the environmental conditions that influence the biofilm formation of this bacterial species. Here, we evaluated the influence of some common culture conditions on G. vaginalis biofilm formation, namely inoculum concentration, incubation period, feeding conditions and culture medium composition. Our results showed that culture conditions strongly influenced $G$. vaginalis biofilm formation and that biofilm formation was enhanced when starting the culture with a higher inoculum, using a fed-batch system and supplementing the growth medium with maltose.
\end{abstract}

(c) 2015 Elsevier B.V. All rights reserved.

\section{Introduction}

Bacterial vaginosis (BV) is the most common gynaecological condition in women of reproductive age and it has been associated with serious health problems including preterm birth, spontaneous abortion, pelvic inflammatory disease, postoperative gynaecologic infections and increased risk of acquisition and transmission of several sexual transmitted agents (Schwebke, 2009). This disorder is characterized by a complex imbalance of vaginal microflora which includes a loss of lactobacilli, principally hydrogen peroxide and lactic acid producing strains, and a concurrent massive overgrowth of Gardnerella vaginalis and other anaerobic bacteria (Verhelst et al., 2004).

Despite of its high prevalence and impact on woman health, BV aetiology remains a matter of debate (Josey and Schwebke, 2008). Importantly, it has been described that BV involves the presence of an adherent biofilm on the vaginal epithelium, being G. vaginalis the predominant bacterial species (Swidsinski et al., 2005). This bacterial biofilm persists after therapy with metronidazole, suggesting that G. vaginalis biofilm plays a key role in BV recurrence (Swidsinski et al., 2008). However, not all G. vaginalis causes BV and it has been recently proposed that only isolates able to form cohesive biofilms could induce BV (Swidsinski et al., 2010). Therefore, assessing the biofilm formation ability of clinical isolates of $G$. vaginalis can highlight their virulence

\footnotetext{
* Corresponding author.

E-mail address: nunocerca@ceb.uminho.pt (N. Cerca).
}

potential. Nevertheless, very little information exists regarding in vitro biofilm quantification by G. vaginalis (Alves et al., 2014; Harwich et al., 2010; Patterson et al., 2010). It is well known that several factors can influence biofilm formation, namely growth medium composition (Kennedy and O'Gara, 2004), feeding conditions (Cerca et al., 2004), inoculum concentration (Cotter et al., 2009), incubation period (Abdallah et al., 2014), temperature (Uhlich et al., 2014), atmosphere conditions (Reuter et al., 2010), surface properties (Cerca et al., 2005) and hydrodynamics (Kim et al., 2013). Thus, our aim was to assess how $G$. vaginalis biofilms were influenced by the most common used variables in in vitro biofilm quantification studies, namely the bacterial inoculum concentration, incubation period, feeding conditions and culture medium composition.

\section{Material and methods}

\subsection{Strains and growth conditions}

Four strains of $G$. vaginalis recently isolated from women with BV were used (Castro et al., 2015). These strains were kept frozen in Brain Heart Infusion (BHI; Liofilchem, Roseto degli Abruzzi, Italy) with 23\% (v/v) glycerol (Panreac, Castellar del Vallès, Barcelona, Spain) at $-80{ }^{\circ} \mathrm{C}$. After thawing, strains were subcultured on columbia blood agar (Liofilchem) supplemented with $5 \%(\mathrm{v} / \mathrm{v})$ defibrinated horse blood (Oxoid Ltd., Basingstoke, Hampshire, United Kingdom) and incubated anaerobically at $37^{\circ} \mathrm{C}$ for $48-72 \mathrm{~h}$. 


\subsection{Biofilm formation}

For the biofilm formation assay, pre-inoculums were prepared through inoculation of grown cultures of $G$. vaginalis in sBHI [BHI supplemented by $2 \%(\mathrm{wt} / \mathrm{v})$ gelatin (Liofilchem), $1 \%(\mathrm{wt} / \mathrm{v})$ yeast extract (Liofilchem), 0.1\% (wt/v) soluble starch (Panreac)]. These preinoculums were incubated at $37{ }^{\circ} \mathrm{C}$ during $24 \mathrm{~h}$ with $10 \% \mathrm{CO}_{2}$ (Shel Lab, Cornelius, Oregon, USA). After incubation, bacterial density was adjusted to $10^{8}$ or $10^{6} \mathrm{CFU} / \mathrm{mL}$ in the $\mathrm{SBHI}$, whenever appropriated. Then, $100 \mu \mathrm{L}$ of each suspension was transferred to each well of a 96-well microplate (Orange Scientific, Braine-l'Alleud, Belgium) and the plates were incubated at $37{ }^{\circ} \mathrm{C}$ with $10 \% \mathrm{CO}_{2}$ during $12 \mathrm{~h}, 24 \mathrm{~h}$ or $48 \mathrm{~h}$, whenever appropriated. Also, a negative control containing only a sterile medium was included. In order to evaluate the effect of fed-batch growth on $48 \mathrm{~h}$ biofilms, the culture medium was replaced by a fresh medium after $24 \mathrm{~h}$ of growth. To assess the influence of culture medium composition on $G$. vaginalis biofilm formation the sBHI medium was supplemented with $0.25 \%$ (wt/v) of each carbohydrate: glucose (Panreac AppliChem, Darmstadt, Germany), dextrin (Fluka Biochemika, Bucks, Switzerland), maltose (Fisher Bioreagents, Fair Lawn, New Jersey, USA) and ribose (Sigma-Aldrich, St. Louis, Missouri, USA). All assays were repeated at least three times with eight technical replicates.

\subsection{Biofilm quantification}

Biofilm biomass was quantified using the crystal violet (CV) staining method previously described by Peeters et al. (2008) with some minor modifications. Briefly, after biofilm formation, the spent medium was removed and the pre-formed biofilms were washed with $200 \mu \mathrm{L}$ of phosphate buffered saline [PBS composed by $16 \mathrm{~g} / \mathrm{L}$ of sodium chloride ( $\mathrm{NaCl}$; Liofilchem); $0.4 \mathrm{~g} / \mathrm{L}$ of potassium chloride $(\mathrm{KCl}$, José M. Vaz Pereira S.A., Benavente, Portugal); $1.62 \mathrm{~g} / \mathrm{L}$ of disodium phosphate dihydrate $\left(\mathrm{Na}_{2} \mathrm{HPO}_{4} \cdot 2 \mathrm{H}_{2} \mathrm{O}\right.$; José M. Vaz Pereira S.A.) and $0.4 \mathrm{~g} / \mathrm{L}$ of potassium dihydrogen phosphate $\left(\mathrm{KH}_{2} \mathrm{PO}_{4}\right.$, José M. Vaz Pereira S.A.] per well of a 96-well microplate. Afterwards, biofilms were fixed with $100 \mu \mathrm{L}$ of $99 \%$ (v/v) methanol (Valente e Ribeiro Lda, Belas, Portugal) per well. After $15 \mathrm{~min}$, supernatants were removed and the microplates were air-dried. Then, biofilms were stained with $100 \mu \mathrm{L}$ of $0.5 \%$ (wt/v) of CV (Acros Organics, Morris Plains, New Jersey, USA) during 20 min. Afterwards, the plates were washed twice with $200 \mu \mathrm{L}$ of PBS to remove the excess CV. Finally, CV was solubilized by adding $150 \mu \mathrm{L}$ of $33 \%$ (v/v) acetic acid (Fisher Scientific, Loughborough, Leicestershire, United Kingdom) per well and the microplates were gently mixed. The optical density (OD) at $590 \mathrm{~nm}$ was measured, using the 96-well microplate reader (Bio-Tek Synergy HT, Winooski, Vermont, USA).

\subsection{Statistical analysis}

Data were analysed using Wilcoxon signed rank test with statistical package for the social science 17.0 software (SPSS; Chicago, Illinois, USA) since the data did not follow a normal distribution according Kolmogorov-Smirnov's test. Statistical differences were considered significant at $P$ values $<0.05$.

\section{Results and discussion}

Biofilm formation enables single-cell microorganisms to assume a temporary multicellular lifestyle, in which collective behaviour facilitates microbial survival and persistency in unfavourable conditions (Donlan and Costerton, 2002). Moreover, biofilm-forming ability has been related with pathogenesis of several human infections, being one of its hallmarks the increased resistance to antimicrobials (Ciofu et al., 2015; Deva et al., 2013). Particularly, the biofilm formation by G. vaginalis constitutes an important virulence factor of this microorganism (Patterson et al., 2010, 2007) and it has been associated with BV occurrence (Swidsinski et al., 2010). While biofilm formation has been

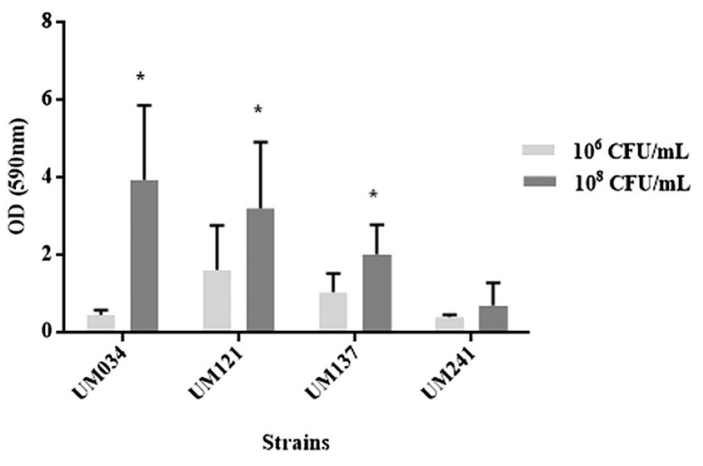

Fig. 1. Influence of inoculum concentration on $G$. vaginalis biofilm formation. Biofilms were grown in sBHI at $37^{\circ} \mathrm{C}$ with $10 \% \mathrm{CO}_{2}$ during $24 \mathrm{~h}$. Statistical differences in the biofilm formation using an inoculum concentration of the $10^{6} \mathrm{CFU} / \mathrm{mL}$ or $10^{8} \mathrm{CFU} / \mathrm{mL}$ are marked with * $(P<0.05)$.

well studied in many bacterial pathogens (Abdallah et al., 2015; Cerca et al., 2005; Crémet et al., 2013), there has not been detailed information regarding biofilm formation by $G$. vaginalis. In this sense, we designed a series of in vitro assays in order to investigate the influence of some culture conditions on $G$. vaginalis biofilm formation.

\subsection{Influence of inoculum concentration and incubation time on G. vaginalis biofilm formation}

It has been demonstrated that inoculum concentration can considerably influence the amount of biofilm produced (Cotter et al., 2009). Commonly, an inoculum concentration of $10^{6} \mathrm{CFU} / \mathrm{mL}$ (Baldoni et al., 2010; Wu et al., 2014) or $10^{8} \mathrm{CFU} / \mathrm{mL}$ (Kostaki et al., 2012; Peeters et al., 2008) has been used in biofilm assays. Therefore, we started to assess the influence of inoculum concentration on biofilm formation, testing these two inoculum concentrations. As shown in Fig. 1, the majority of strains tested yielded a significant higher biofilm when we used an inoculum concentration of $10^{8} \mathrm{CFU} / \mathrm{mL}$. These results were not surprising and can be justified by the slow growth rate of the G. vaginalis. However, it was plausible to assume that, if given enough time, the smaller inocula could potentially reach the higher levels of biofilm formation. Generally, the density of biofilm increases with prolongation of incubation until an optimal incubation time is reached (Mathur et al., 2006). However, since mature biofilms are known to suffer shedding, by releasing cells to the surrounding environment (Boles et al., 2005; Kaplan et al., 2003), the effect of the incubation time needed to be experimentally assessed. To determine how the incubation period would

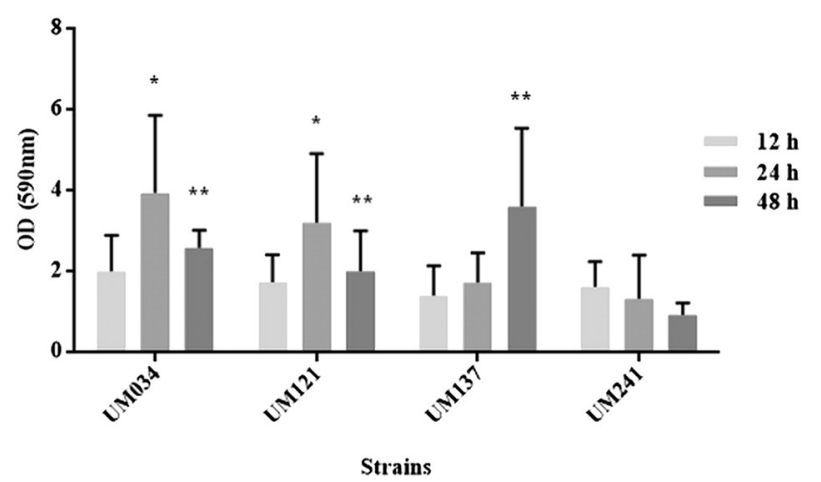

Fig. 2. Influence of incubation time on $G$. vaginalis biofilm formation. Biofilms were grown in sBHI at $37^{\circ} \mathrm{C}$ with $10 \% \mathrm{CO}_{2}$ during $12 \mathrm{~h}, 24 \mathrm{~h}$ and $48 \mathrm{~h}$. Statistical differences in the biofilm formation using an incubation time of $12 \mathrm{~h}$ and $24 \mathrm{~h}$ are marked with ${ }^{*}(P<0.05)$, while statistical differences between $24 \mathrm{~h}$ and $48 \mathrm{~h}$ are marked with ${ }^{* *}(P<0.05)$. 


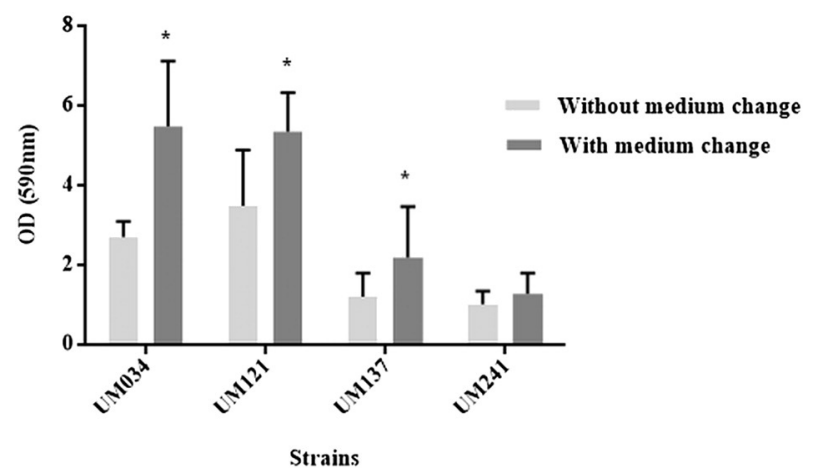

Fig. 3. Influence of feeding conditions on $G$. vaginalis biofilm formation. Biofilms were grown in sBHI at $37{ }^{\circ} \mathrm{C}$ with $10 \% \mathrm{CO}_{2}$ during $48 \mathrm{~h}$. The culture medium change was performed after $24 \mathrm{~h}$ of incubation. Statistical differences in the biofilm formation with or without medium change are marked with * $(P<0.05)$.

influence the biofilm accumulation, we inoculated the $10^{8} \mathrm{CFU} / \mathrm{mL}$ bacterial suspension in the 96-well microplates and the plates were incubated during $12 \mathrm{~h}, 24 \mathrm{~h}$ and $48 \mathrm{~h}$. Interestingly, strain to strain variability, with opposite trends, was detected in biofilm-forming ability, over time. As can be seen in Fig. 2, strain UM 241 did not significantly changed the biofilm formation (Wilcoxon test; $P>0.05$ ), contrary to strain UM 137 that showed a significant increase in biofilm formation at $48 \mathrm{~h}$ (Wilcoxon test, $P<0.05$ ). On the other hand, strains UM034 and UM121 increased biofilm biomass from $12 \mathrm{~h}$ to $24 \mathrm{~h}$, but then a reduction of biomass was detected, from $24 \mathrm{~h}$ to $48 \mathrm{~h}$. This suggested that, in these strains, nutrient depletion or waste-product accumulation, over time, could be affecting biofilm accumulation (Delaquis et al., 1989; Sawyer and Hermanowicz, 2000).

\subsection{Influence of feeding conditions on $\mathrm{G}$. vaginalis biofilm formation}

Next, we tested whether changing the culture media, after $24 \mathrm{~h}$ of growth, would enhance the biomass at $48 \mathrm{~h}$ biofilms, particularly in strains UM034 and UM121. As shown in Fig. 3, this approach allowed an increase in biofilm biomass on those strains. These results are in agreement with previous reports that demonstrated that the fedbatch growth was a favourable culture condition for biofilm formation in many other species (Cerca et al., 2004; Pongtharangkul and Demirci, 2006; Rodrigues et al., 2009).

\subsection{Influence of culture medium carbohydrate source on G. vaginalis biofilm formation}

Despite all the tested incubation conditions, we still observed that biofilm formation by strain UM 241 was not being affected. Probably one of the most important factors is the culture medium composition. We used sBHI as the base medium, since this was previously shown to be a good media for many BV-associated bacteria (Alves et al., 2014). However, it has been described that the biofilm formation is widely affected by the presence of certain carbon substrates in the culture medium (Kalai Chelvam et al., 2015; Rinaudi et al., 2006). In a detailed biochemical profile study using 78 G. vaginalis strains, more than $97 \%$ of the tested strains were able to metabolize glucose, dextrin, maltose and ribose (Greenwood and Pickett, 1979). In this sense we evaluated the effect of supplementation of sBHI with $0.25 \%$ (wt/v) of the mentioned carbohydrates on $G$. vaginalis biofilm formation. Interestingly, as can be seen in Fig. 4, maltose was the only carbohydrate that enhanced biofilm formation in all tested strains, while ribose had the opposite effect. Glucose and dextrin enhanced biofilm formation of some strains, but generally to a lesser extent than maltose. Either glucose, dextrin or maltose has been associated with increasing the amount of biofilm formed by several bacterial species, such as Listeria monocytogenes (Pan et al., 2010), Salmonella enterica (Kalai Chelvam et al., 2015) and Enterococcus faecalis (Creti et al., 2006). In contrast, the presence of ribose in a culture medium was related with a decrease of biofilm formation by Streptococcus mutans, Streptococcus sobrinus (Lee et al., 2015) and Aggregatibacter actinomycetemcomitans (Shao et al., 2007). Ribose inhibits biofilm formation through interrupting bacterial quorum sensing, due to its structural similarity with auto-inducer 2 (AI-2), since it bears a furanosyl borate diester form (Cao and Meighen, 1989). Previous data showed that ribose compete with AI-2 for binding to RbsB (ribose binding subunit $B$, one of the subunits of the ribose $\mathrm{ABC}$ transporter) and subsequently interfere AI-2-dependent phenotypes such as biofilm formation in A. actinomycetemcomitans (Shao et al., 2007). However, up to now, no information is available about the possible role of AI-2 in G. vaginalis biofilm formation.

\section{Conclusion}

This is the first study to quantify in vitro biofilm formation by clinical G. vaginalis strains. While previous studies used glucose as a biofilm inducer in $G$. vaginalis, our data shows that maltose is a preferable source of carbohydrates. Furthermore, a fed-batch system allows for thicker biofilms to be formed, as compared with batch.

However, it is doubtful that these optimized in vitro conditions can mimic the in vivo phenomena. Even so, the optimization of biofilm formation seems reasonable for both screening and fundamental studies, in order to better study this type of bacterial community.

\section{Acknowledgements}

The authors thank the FCT Strategic Project of UID/BIO/04469/2013 unit, the project NORTE-07-0124-FEDER-000027, co-funded by the Programa Operacional Regional do Norte (ON.2 - O Novo Norte),

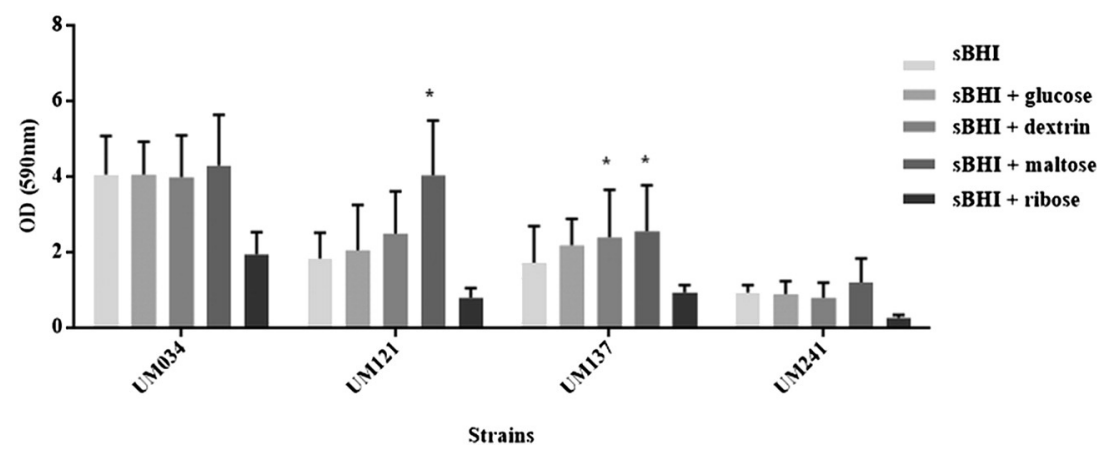

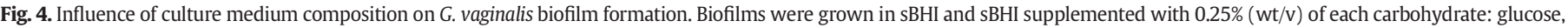

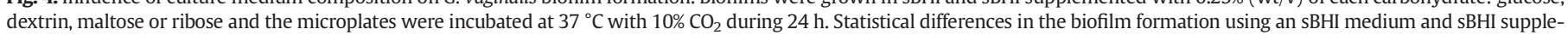
mented with each carbohydrate are marked with ${ }^{*}(P<0.05)$. 
QREN, FEDER, and the project RECI/BBB-EBI/0179/2012 (FCOMP-010124-FEDER-027462). DM acknowledges the FCT fellowship SFRH/BD/ 87569/2012. NC is an Investigator of FCT.

\section{References}

Abdallah, M., Benoliel, C., Ferreira-Theret, P., Drider, D., Dhulster, P., Chihib, N.E., 2015. Effect of culture conditions on the resistance of Pseudomonas aeruginosa biofilms to disinfecting agents. Biofouling 31, 49-59. http://dx.doi.org/10.1080/08927014.2014. 993390.

Abdallah, M., Chataigne, G., Ferreira-Theret, P., Benoliel, C., Drider, D., Dhulster, P., Chihib, N.E., 2014. Effect of growth temperature, surface type and incubation time on the resistance of Staphylococcus aureus biofilms to disinfectants. Appl. Microbiol. Biotechnol. 98, 2597-2607. http://dx.doi.org/10.1007/s00253-013-5479-4.

Alves, P. Castro, J., Sousa, C., Cereija, T.B., Cerca, N., 2014 Gardnerella vaginalis outcompetes 29 other bacterial species isolated from patients with bacterial vaginosis, using in an in vitro biofilm formation model. J. Infect. Dis. 210, 593-596. http://dx. doi.org/10.1093/infdis/jiu131.

Baldoni, D., Steinhuber, A., Zimmerli, W., Trampuz, A., 2010. In vitro activity of gallium maltolate against staphylococci in logarithmic, stationary, and biofilm growth phases: comparison of conventional and calorimetric susceptibility testing methods. Antimicrob. Agents Chemother. 54, 157-163. http://dx.doi.org/10.1128/AAC.0070009.

Boles, B.R., Thoendel, M., Singh, P.K., 2005. Rhamnolipids mediate detachment of Pseudomonas aeruginosa from biofilms. Mol. Microbiol. 57, 1210-1223. http://dx.doi.org/10. 1111/j.1365-2958.2005.04743.x.

Cao, J.G., Meighen, E.A., 1989. Purification and structural identification of an autoinducer for the luminescence system of Vibrio harveyi. J. Biol. Chem. 264, 21670-21676.

Castro, J., Alves, P., Sousa, C., Cereija, T., França, Â., Jefferson, K.K., Cerca, N., 2015. Using an in-vitro biofilm model to assess the virulence potential of bacterial vaginosis or nonbacterial vaginosis Gardnerella vaginalis isolates. Sci. Rep. 5, 11640. http://dx.doi.org/ $10.1038 /$ srep11640.

Cerca, N., Pier, G.B., Vilanova, M., Oliveira, R., Azeredo, J., 2004. Influence of batch or fedbatch growth on Staphylococcus epidermidis biofilm formation. Lett. Appl. Microbiol. 39, 420-424. http://dx.doi.org/10.1111/j.1472-765X.2004.01601.x.

Cerca, N., Pier, G.B., Vilanova, M., Oliveira, R., Azeredo, J., 2005. Quantitative analysis of adhesion and biofilm formation on hydrophilic and hydrophobic surfaces of clinical isolates of Staphylococcus epidermidis. Res. Microbiol. 156, 506-514. http://dx.doi.org/10. 1016/j.resmic.2005.01.007.

Ciofu, O., Tolker-Nielsen, T., Jensen, P.Ø., Wang, H., Høiby, N., 2015. Antimicrobial resistance, respiratory tract infections and role of biofilms in lung infections in cystic fibrosis patients. Adv. Drug Deliv. Rev. 85, 7-23. http://dx.doi.org/10.1016/j.addr.2014.11. 017.

Cotter, J.J., O'Gara, J.P., Casey, E., 2009. Rapid depletion of dissolved oxygen in 96-well microtiter plate Staphylococcus epidermidis biofilm assays promotes biofilm development and is influenced by inoculum cell concentration. Biotechnol. Bioeng. 103. 1042-1047. http://dx.doi.org/10.1002/bit.22335.

Crémet, L., Corvec, S., Batard, E., Auger, M., Lopez, I., Pagniez, F., Dauvergne, S., Caroff, N., 2013. Comparison of three methods to study biofilm formation by clinical strains of Escherichia coli. Diagn. Microbiol. Infect. Dis. 75, 252-255. http://dx.doi.org/10.1016/ j.diagmicrobio.2012.11.019.

Creti, R., Koch, S., Fabretti, F., Baldassarri, L., Huebner, J., 2006. Enterococcal colonization of the gastro-intestinal tract: role of biofilm and environmental oligosaccharides. BMC Microbiol. 6, 60. http://dx.doi.org/10.1186/1471-2180-6-60.

Delaquis, P.J., Caldwell, D.E., Lawrence, J.R., McCurdy, A.R., 1989. Detachment of Pseudomonas fluorescens from biofilms on glass surfaces in response to nutrient stress. Microb. Ecol. 18, 199-210. http://dx.doi.org/10.1007/BF02075808.

Deva, A.K., Adams, W.P., Vickery, K., 2013. The role of bacterial biofilms in deviceassociated infection. Plast. Reconstr. Surg. 132, 1319-1328. http://dx.doi.org/10. 1097/PRS.0b013e3182a3c105.

Donlan, R.M., Costerton, J.W., 2002. Biofilms: survival mechanisms of clinically relevant microorganisms. Clin. Microbiol. Rev. 15, 167-193. http://dx.doi.org/10.1128/CMR. 15.2.167-193.2002.

Greenwood, J.R., Pickett, M.J., 1979. Salient features of Haemophilus vaginalis. J. Clin. Microbiol. 9, 200-204.

Harwich, M.D., Alves, J.M., Buck, G.A., Strauss, J.F., Patterson, J.L., Oki, A.T., Girerd, P.H., Jefferson, K.K., 2010. Drawing the line between commensal and pathogenic Gardnerella vaginalis through genome analysis and virulence studies. BMC Genomics 11, 375. http://dx.doi.org/10.1186/1471-2164-11-375.

Josey, W.E., Schwebke, J.R., 2008. The polymicrobial hypothesis of bacterial vaginosis causation: a reassessment. Int. J. STD AIDS 19, 152-154. http://dx.doi.org/10.1258/ijsa. 2007.007260.

Kalai Chelvam, K., Yap, K.P., Chai, L.C., Thong, K.L., 2015. Variable responses to carbon utilization between planktonic and biofilm cells of a human carrier strain of Salmonella enterica serovar typhi. PLoS One 10, e0126207. http://dx.doi.org/10.1371/journal. pone.0126207.

Kaplan, J.B., Meyenhofer, M.F., Fine, D.H., 2003. Biofilm growth and detachment of Actinobacillus actinomycetemcomitans. J. Bacteriol. 185, 1399-1404. http://dx.doi. org/10.1128/JB.185.4.1399-1404.2003.
Kennedy, C.A., O'Gara, J.P., 2004. Contribution of culture media and chemical properties of polystyrene tissue culture plates to biofilm development by Staphylococcus aureus. J. Med. Microbiol. 53, 1171-1173. http://dx.doi.org/10.1099/jmm.0.45764-0.

Kim, J., Kim, H.S., Han, S., Lee, J.Y., Oh, J.E., Chung, S., Park, H.D., 2013. Hydrodynamic effects on bacterial biofilm development in a microfluidic environment. Lab Chip 13 , 1846-1849. http://dx.doi.org/10.1039/c3lc40802g.

Kostaki, M., Chorianopoulos, N., Braxou, E., Nychas, G.J., Giaouris, E., 2012. Differential biofilm formation and chemical disinfection resistance of sessile cells of Listeria monocytogenes strains under monospecies and dual-species (with Salmonella enterica) conditions. Appl. Environ. Microbiol. 78, 2586-2595. http://dx.doi.org/10. 1128/AEM.07099-11.

Lee, H.J., Kim, S.C., Kim, J., Do, A., Han, S.Y., Lee, B.D., Lee, H.H., Lee, M.C., Lee, S.H., Oh, T., Park, S., Hong, S.H., 2015. Synergistic inhibition of streptococcal biofilm by ribose and xylitol. Arch. Oral Biol. 60, 304-312. http://dx.doi.org/10.1016/j.archoralbio. 2014.11.004.

Mathur, T., Singhal, S., Khan, S., Upadhyay, D.J., Fatma, T., Rattan, A., 2006. Detection of biofilm formation among the clinical isolates of staphylococci: an evaluation of three different screening methods. Indian J. Med. Microbiol. 24, 25-29. http://dx.doi.org/10. 4103/0255-0857.19890.

Pan, Y., Breidt, F., Gorski, L., 2010. Synergistic effects of sodium chloride, glucose, and temperature on biofilm formation by Listeria monocytogenes serotype $1 / 2 \mathrm{a}$ and $4 \mathrm{~b}$ strains Appl. Environ. Microbiol. 76, 1433-1441. http://dx.doi.org/10.1128/AEM.02185-09.

Patterson, J.L., Girerd, P.H., Karjane, N.W., Jefferson, K.K., 2007. Effect of biofilm phenotype on resistance of Gardnerella vaginalis to hydrogen peroxide and lactic acid. Am. J. Obstet. Gynecol. 197, 170.e1-170.e7. http://dx.doi.org/10.1016/j.ajog.2007.02.027.

Patterson, J.L., Stull-Lane, A., Girerd, P.H., Jefferson, K.K., 2010. Analysis of adherence, biofilm formation and cytotoxicity suggests a greater virulence potential of Gardnerella vaginalis relative to other bacterial-vaginosis-associated anaerobes. Microbiology 156, 392-399. http://dx.doi.org/10.1099/mic.0.034280-0.

Peeters, E., Nelis, H.J., Coenye, T., 2008. Comparison of multiple methods for quantification of microbial biofilms grown in microtiter plates. J. Microbiol. Methods 72, 157-165. http://dx.doi.org/10.1016/j.mimet.2007.11.010.

Pongtharangkul, T., Demirci, A., 2006. Effects of fed-batch fermentation and pH profiles on nisin production in suspended-cell and biofilm reactors. Appl. Microbiol. Biotechnol. 73, 73-79. http://dx.doi.org/10.1007/s00253-006-0459-6.

Reuter, M., Mallett, A., Pearson, B.M., van Vliet, A.H.M., 2010. Biofilm formation by Campylobacter jejuni is increased under aerobic conditions. Appl. Environ. Microbiol. 76, 2122-2128. http://dx.doi.org/10.1128/AEM.01878-09.

Rinaudi, L., Fujishige, N.A., Hirsch, A.M., Banchio, E., Zorreguieta, A., Giordano, W., 2006. Effects of nutritional and environmental conditions on Sinorhizobium meliloti biofilm formation. Res. Microbiol. 157, 867-875. http://dx.doi.org/10.1016/j.resmic.2006.06. 002.

Rodrigues, D.A., Almeida, M.A., Teixeira, P.A., Oliveira, R.T., Azeredo, J.C., 2009. Effect of batch and fed-batch growth modes on biofilm formation by Listeria monocytogenes at different temperatures. Curr. Microbiol. 59, 457-462. http://dx.doi.org/10.1007/ s00284-009-9460-5.

Sawyer, L.K., Hermanowicz, S.W., 2000. Detachment of Aeromonas hydrophila and Pseudomonas aeruginosa due to variations in nutrient supply. Water Sci. Technol. 41, 139-145.

Schwebke, J.R., 2009. New concepts in the etiology of bacterial vaginosis. Curr. Infect. Dis. Rep. 11, 143-147. http://dx.doi.org/10.1007/s11908-009-0021-7.

Shao, H., Lamont, R.J., Demuth, D.R., 2007. Autoinducer 2 is required for biofilm growth of Aggregatibacter (Actinobacillus) actinomycetemcomitans. Infect. Immun. 75, 4211-4218. http://dx.doi.org/10.1128/IAI.00402-07.

Swidsinski, A., Doerffel, Y., Loening-Baucke, V., Swidsinski, S., Verstraelen, H. Vaneechoutte, M., Lemm, V., Schilling, J., Mendling, W., 2010. Gardnerella biofilm involves females and males and is transmitted sexually. Gynecol. Obstet. Investig. 70, 256-263. http://dx.doi.org/10.1159/000314015.

Swidsinski, A., Mendling, W., Loening-Baucke, V., Ladhoff, A., Swidsinski, S., Hale, L.P., Lochs, H., 2005. Adherent biofilms in bacterial vaginosis. Obstet. Gynecol. 106, 1013-1023. http://dx.doi.org/10.1097/01.AOG.0000183594.45524.d2.

Swidsinski, A., Mendling, W., Loening-Baucke, V., Swidsinski, S., Dörffel, Y., Scholze, J., Lochs, H., Verstraelen, H., 2008. An adherent Gardnerella vaginalis biofilm persists on the vaginal epithelium after standard therapy with oral metronidazole. Am. J. Obstet. Gynecol. 198, 97.e1-6. http://dx.doi.org/10.1016/j.ajog.2007.06.039.

Uhlich, G.A., Chen, C.Y., Cottrell, B.J., Nguyen, L.H., 2014. Growth media and temperature effects on biofilm formation by serotype 0157:H7 and non-0157 Shiga toxinproducing Escherichia coli. FEMS Microbiol. Lett. 354, 133-141. http://dx.doi.org/10. 1111/1574-6968.12439.

Verhelst, R., Verstraelen, H., Claeys, G., Verschraegen, G., Delanghe, J., Van Simaey, L., De Ganck, C., Temmerman, M., Vaneechoutte, M., 2004. Cloning of 16S rRNA genes amplified from normal and disturbed vaginal microflora suggests a strong association between Atopobium vaginae, Gardnerella vaginalis and bacterial vaginosis. BMC Microbiol. 4, 16. http://dx.doi.org/10.1186/1471-2180-4-16.

Wu, X., Santos, R.R., Fink-Gremmels, J., 2014. Staphylococcus epidermidis biofilm quantification: effect of different solvents and dyes. J. Microbiol. Methods 101, 63-66. http:// dx.doi.org/10.1016/j.mimet.2014.03.016. 